\title{
Analysis on The Idling Energy Consumption of Machine Tools during Its Operation Cycle
}

\author{
Shuang Liu*, Xiang Li and Zhenzhen Lei \\ College of Mechanical and Power Engineering, Chongqing University of Science \& Technology, Chongqing 401331, China \\ ${ }^{*}$ Corresponding author
}

\begin{abstract}
Rhymes with the large amount of energy loss during the operation cycle of machine tools, environmental contamination occurs simultaneously. To cut down the energy cost, there is a growing need to research into the basic rules of energy consumption of machine tools. This paper focuses on the energy consumption laws of machine tools during idling period. energy consumption of machine tools over a period of time was monitored, through which a hypothesis was proposed that the idling power is related to the spindle speed. This hypothesis was verified by later conducted experiments. Two kinds of relationships were clarified, and the accuracy of the fitting curves were proved.
\end{abstract}

\section{Keywords-energy consumption; machine tools; idling}

\section{INTRODUCTION}

On the background advent of low carbon economy, energy conservation and emmission reduction gradually turn into leading factor for future conomic growth.[1]Worldwide governments are all formulating policies on this field. U. S. Council for Energy_Efficient Manufacturing was established to reduce energy intesity of manufacturing.[2] China's National Outline for Medium and Long Term S\&T Development also aims to promote the energy consumption of manufacturing industry to international advanced level.[3]

In a manufacturing system, machine tools plays foundational role. However, the energy consumpiton and equivalent let out of machine tools are also considerable. During the use phase of a milling machine, there's $60 \%$ to $90 \%$ of equivalent $\mathrm{CO} 2$ given off.[4] It's urgent to probe into the energy consumption of machine tools. The idling power is very important in the energy consumption of machine tools, as it exits not only in the idling time, but also in cutting time . There used to be function of the power of machine tools[5], nevertheless the intricate theoritical parameters of the mode is too difficult to obtain. Therefore, this paper focuses on the practical analysis of idling energy of machine tools. large number of experiments were carried out to find out the internal law of energy consumption of machine tools.

\section{CONSTITUTION OF IDLE ENERGY CONSUMPTION OF MACHINE TOOLS}

When a machine tool is powered on, there's absolutely certain degree of energy consumption. We define the time between startup and shutdown as the operation cycle of the energy consumption of machine tools. In an operation cycle, there can be four types of operation, which covers start up, acceleration, zero load, and cutting[6]. Actually, except for the cutting operation, all the other three types are all operations with zero load. In order to separate from start up and acceleration, we call the third type of opertion idling. Idling means the machine tool is not only powered on, but also revolving its spindle without contact between workpiece and cutting tool.

Many kinds of movements of machine tool can be classified into idling. Rapid traverse is the first category of idling. The cutting tool moves to the destination at very high feed rate while the spindle keeps rotating. When the cutting tool get close to the initial cutting point, approach motion, the second category of idling begin. Drawing back of the tool after cutting is another type of idling, in which process only the direction of cutting tool movement is opposite from approach. This process is also called escape. Besides these three kinds of idling, there may also be other types of idling on special occasions. Figure 1 give a brief presentation of the constitution of operation cycle and idling.

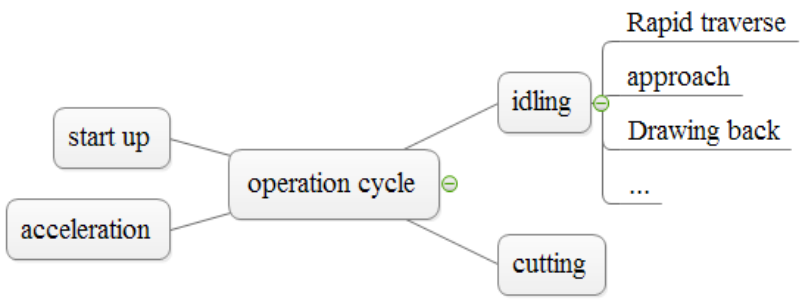

FIGURE I. CONSTITUTION OF OPERATION CYCLE AND IDLING

\section{HYPOTHESIS}

The idling power consumption of machine tools was monitored for a period time while spindle speed remain unchanged. Under the sampling frequency of 1sps, a number of power values were obtained. Table 1 only gives a section of the whole.

As shown in Table 1, four different spindle speed were selected to repeat the idling power monitoring experiment. According to Table 1, a comparison graph about the power change over time was drawn as Figure 2. 
TABLE I. Energy Consumption Of MAchine Tools Over A Period Of Time

\begin{tabular}{|c|c|c|c|c|c|c|c|}
\hline \multicolumn{7}{|c|}{ Spindle Speed (rpm) } \\
\hline \multicolumn{2}{|c|}{100} & \multicolumn{2}{c|}{600} & \multicolumn{2}{c|}{2000} \\
\hline time & power & time & power & time & power & time & power \\
\hline $19: 40: 51$ & 64.41 & $20: 01: 48$ & 119.49 & $20: 22: 34$ & 167.29 & $20: 56: 42$ & 217.31 \\
\hline $19: 40: 52$ & 65.75 & $20: 01: 49$ & 123.42 & $20: 22: 35$ & 173.92 & $20: 56: 43$ & 213.24 \\
\hline $19: 40: 53$ & 69.15 & $20: 01: 50$ & 119.36 & $20: 22: 36$ & 187.42 & $20: 56: 44$ & 223.71 \\
\hline $19: 40: 54$ & 69.74 & $20: 01: 51$ & 119.23 & $20: 22: 37$ & 190.01 & $20: 56: 45$ & 237.06 \\
\hline $19: 40: 55$ & 68.68 & $20: 01: 52$ & 120.57 & $20: 22: 38$ & 164.91 & $20: 56: 46$ & 204.49 \\
\hline $19: 40: 56$ & 68.96 & $20: 01: 53$ & 122.35 & $20: 22: 39$ & 165.84 & $20: 56: 47$ & 211.55 \\
\hline $19: 40: 57$ & 69.61 & $20: 01: 54$ & 121.06 & $20: 22: 40$ & 177.25 & $20: 56: 48$ & 214.91 \\
\hline $19: 40: 58$ & 67.56 & $20: 01: 55$ & 119.35 & $20: 22: 41$ & 189.61 & $20: 56: 49$ & 204.48 \\
\hline $19: 40: 59$ & 66.14 & $20: 01: 56$ & 114.63 & $20: 22: 42$ & 194.98 & $20: 56: 50$ & 245.30 \\
\hline $19: 41: 00$ & 65.28 & $20: 01: 57$ & 116.81 & $20: 22: 43$ & 163.25 & $20: 56: 51$ & 206.89 \\
\hline $19: 41: 01$ & 63.58 & $20: 01: 58$ & 121.85 & $20: 22: 44$ & 156.07 & $20: 56: 52$ & 204.50 \\
\hline $19: 41: 02$ & 63.54 & $20: 01: 59$ & 122.45 & $20: 22: 45$ & 178.77 & $20: 56: 53$ & 212.52 \\
\hline
\end{tabular}

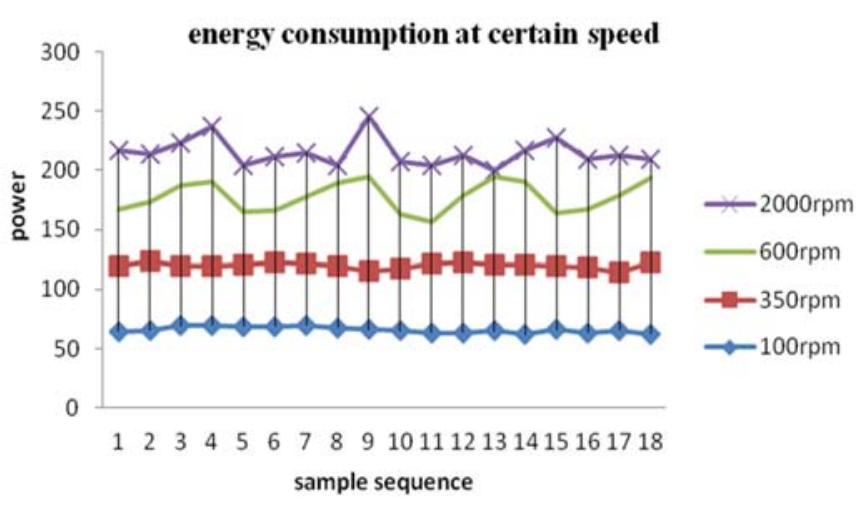

FIGURE II. Energy Consumption Along Time At Certain SPEeD

From this graph, we see that the power value at certain speed fluctuate over time. However, the amplitude of the fluctuation is not very big, especially at lower speeds. According to Eq. 1, amplitude of the fluctuation at these four speeds were calculated, as shown in Table 2.

$$
A_{\mathrm{f}}=\frac{n\left(\mathrm{P}_{\mathrm{mx}}-\mathrm{P}_{\mathrm{mn}}\right)}{\sum_{i=1}^{n} P_{i}}
$$

In Eq. 1, $A_{f}$ refers to the amplitude of the fluctuation; $n$ is the total sample number; $\mathrm{P}_{\mathrm{i}}$ is the power value of the ith sample; $\mathrm{P}_{\mathrm{mx}}$ and $\mathrm{P}_{\mathrm{mn}}$ are separately the maximum and minimum power value of all the samples under the same spindle speed.

TABLE II. Amplitude OF POWER FLuCtuAtion

\begin{tabular}{|c|c|c|c|c|}
\hline Spindle Speed & 100 & 350 & 600 & 2000 \\
\hline Amplitude & $11.6 \%$ & $7.4 \%$ & $21.9 \%$ & $21.2 \%$ \\
\hline
\end{tabular}

We also notice that power values at higher speeds are accordingly higher than those of lower values. Hence, a hypothesis came into being that the idling power of machine tools are correlative to spindle speed. Here the idling power refers to the average power value to leave out the influence of power fluctuation.

\section{VERIFICATION TEST}

To verify the aforementioned hypothesis, several experiments on idling energy consumption were conducted under different spindle speed. For spindle speeds under 1000 rpm, 10 samples were chosen on same spacing of $100 \mathrm{rpm}$. For spindle speeds above $1000 \mathrm{rpm}$, the interval between samples are also the same, but bigger (200rpm).

After the spindle speeds were selected, 3 times of idling power tests were carried out at each of these spindle speeds. Then take the average value of these three different tests as the final idling power, thus the measuring error caused by random factors could be reduced. The final values are presented in Table 3.

TABLE III. IDLING POWER OF TK36 CNC MACHINE TOOLS

\begin{tabular}{|c|c|c|c|}
\hline $\begin{array}{c}\text { Spingdle } \\
\text { Speed } \\
(\mathbf{r p m})\end{array}$ & Idling Power & $\begin{array}{c}\text { Spingdle Speed } \\
\mathbf{( r p m )}\end{array}$ & $\begin{array}{c}\text { Idling } \\
\text { Power }\end{array}$ \\
\hline S100 & 63.9 & S1000 & 174.5 \\
\hline S200 & 86.1 & S1200 & 178 \\
\hline S300 & 103.5 & S1400 & 181.7 \\
\hline S400 & 130.7 & S1600 & 184.8 \\
\hline S500 & 153.6 & S1800 & 196.2 \\
\hline S600 & 174.6 & S2000 & 213.7 \\
\hline S700 & 202.9 & S2200 & 238.2 \\
\hline S800 & 217.4 & S2500 & 272.7 \\
\hline S900 & 193.5 & & \\
\hline
\end{tabular}

To see the change law of idling power, a curve shown in Fig. 3 was drawn according to the values in Table 3. In Fig. 3, there are two obviously different parts. The first part begins from the start point and ends at spindle speed $800 \mathrm{rpm}$, where the idling power reaches the peak of this part without a drop. The rest values forms the second part, where there is there is a decline at the beginning, and a rise afterwards. 


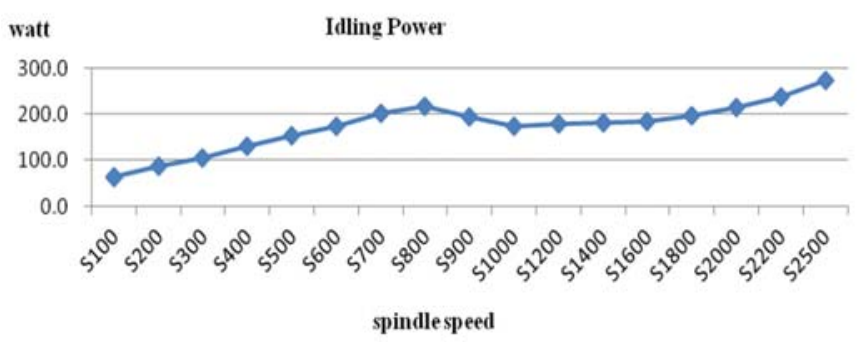

FIGURE III. IDLING POWER AT DIFFERENT SPINDLE SPEEDS

Therefore, different fitting curves were chosen to match these two parts. The first part was fitted by a line, while the second part was fitted by binomial. Eq. 2 and Eq. 3 are the fitting formulas for these two curves.

$$
Y=0.2255 x+40.103
$$

$$
Y=0.000005 x^{2}-0.156 x+276.38
$$

To examine the accuracy of these two fitting formulas, several tests were conducted, the idling power calculated by the two formulas were compared to the measured values. The results in Figure 4 shows the varacity of the formulas. All errors of the testing points are under $7 \%$.

TABLE IV. ERROR OF THE FITTING CURVES

\begin{tabular}{|c|c|c|c|}
\hline Spindle Speed & Fitting Value & $\begin{array}{c}\text { Measured } \\
\text { Value }\end{array}$ & Error \\
\hline 125 & 68.3 & 66.9 & $2.04 \%$ \\
\hline 175 & 79.6 & 78.8 & $1.01 \%$ \\
\hline 225 & 90.8 & 94.5 & $-3.90 \%$ \\
\hline 375 & 124.7 & 124.3 & $0.30 \%$ \\
\hline 475 & 147.2 & 146.5 & $0.50 \%$ \\
\hline 1150 & 176.3 & 182.3 & $-3.29 \%$ \\
\hline 1260 & 175.1 & 172.7 & $1.40 \%$ \\
\hline 1690 & 184.1 & 179.7 & $2.43 \%$ \\
\hline 1930 & 198.8 & 190.2 & $4.54 \%$ \\
\hline 2160 & 219.4 & 205.9 & $6.52 \%$ \\
\hline
\end{tabular}

\section{COMPARATIVE EXPERIMENT}

To check if the kinetic energy of the workpiece would affect the idling power, several comparative experiments were carried out, in which the spindle was revolved with workpiece clamped.

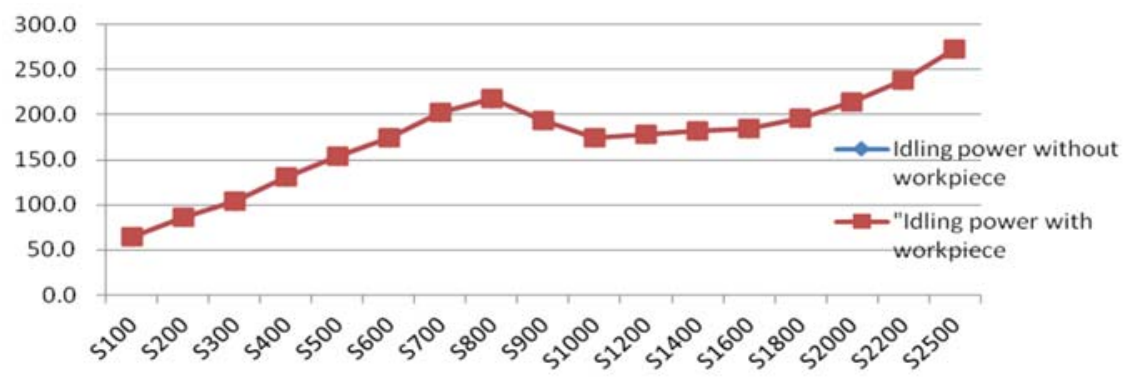

FIGURE IV. IDLING POWER CAMPARED WITH WORKPIECE CLAMPED OR NOT

Figure 4 shows there's barely any difference between the idling power on these two kinds of situation. This phenomenon can be explained by Table 5, which reveals that kinetic energy occupies only a very small percentage of the total idling power.

TABLE V. RATIO OF KINETIC ENERGY IN THE TOTAL IDLING POWER

\begin{tabular}{|c|c|c|c|}
\hline $\begin{array}{c}\text { Spingdle Speed } \\
\text { (rpm) }\end{array}$ & Ratio & $\begin{array}{c}\text { Spingdle Speed } \\
\text { (rpm) }\end{array}$ & Ratio \\
\hline S100 & $0.00047 \%$ & S1000 & $0.01000 \%$ \\
\hline S200 & $0.00014 \%$ & S1200 & $0.02000 \%$ \\
\hline S300 & $0.00026 \%$ & S1400 & $0.03000 \%$ \\
\hline S400 & $0.00037 \%$ & S1600 & $0.04000 \%$ \\
\hline S500 & $0.00049 \%$ & S1800 & $0.05000 \%$ \\
\hline S600 & $0.00062 \%$ & S2000 & $0.06000 \%$ \\
\hline S700 & $0.00073 \%$ & S2200 & $0.06000 \%$ \\
\hline S800 & $0.00089 \%$ & S2500 & $0.07000 \%$ \\
\hline S900 & $0.01000 \%$ & & \\
\hline
\end{tabular}

\section{SUMMARY}

Idling power, which would affect the total energy consumption of machine tools, is closely related to the spindle speed. It increases as the spindle speed goes up, however, at certain point of spindle speed, this linear increasing relationship change to binominal relationship. These two relationship could be precisely described by different fitting curves. In addition, when we measure the idling power of machine tools, the load of workpiece could be omitted, as the kinetic energy of workpiece only occupies small proportion of the total idling power.

\section{ACKNOWLEDGMENT}

The lead author kindly acknowledges the funding provided by the National Natural Science Foundation (Grant No. 51305474), National High Technology Research and Development Program(Grant No. 2014AA041506), and Scientific and Technological Research Program of Chongqing Municipal Education Commission（Grant No. KJ1401320）. 


\section{REFERENCES}

[1] Information on http://www.newenergy.org.cn /html/0098/8120929127.html,2010.

[2] Information on http://www.supefiorenergyperfo-rmance.net/ aboutus.html,2010.

[3] Information on http://news.xinhuanet.com/ziliao/201008/03/content_13957208. htm.

[4] A Dietmair, A Verl, Energy Consumption Forecasting and Optimisation for Tool Machines, Modern Machinery Science Journal. 2009 (3) 62-67.

[5] F LIU, Z.J. XU, B DAN, et al., Energy Characteristic of Mechanical Manufacturing System and its Application, Beijing, 1995.

[6] F LIU, S LIU, Multi-period Energy Model of Electro-mechanical Main Driving System during the Service Process of Machine Tools, Journal of Mechanical Engineering, 2012 (48) 133-140. 